\title{
PEMBUATAN PRECIPITATED CALCIUM CARBONATE (PCC) DARI BATU KAPUR DENGAN METODA KAUSTIK SODA
}

\author{
Novesar Jamarun, Yulfitrin dan Syukri Arief \\ Jurusan Kimia FMIPA, Universitas Andalas
}

\begin{abstract}
ABSTRAK
PCC dapat dihasilkan dari batu kapur melalui tiga metoda yaitu metoda solvay, karbonasi dan metoda kaustik soda. Pada penelitian ini PCC disintesis dengan metoda kaustik soda yang dimodifikasi, yakni dengan mereaksikan batu kapur yang sudah dikalsinasi $(\mathrm{CaO})$ dengan asam nitrat, membentuk garam kalsium nitrat yang mudah larut. Larutan garam yang terbentuk direaksikan dengan larutan natrium karbonat sehingga terbentuk endapan kalsium karbonat (PCC). Berdasarkan analisis XRF kandungan $\mathrm{CaO}$ dalam batu kapur yang diambil dari 5 daerah (Halaban, Lintau Buo, Bukit Tui, Solok, Indarung) di Sumatera Barat berkisar antara 52,79\% sampai 54,93\%, dengan kandungan tertinggi pada daerah Lintau Buo (54,93\%). PCC yang dihasilkan paling banyak diperoleh pada konsentrasi 2,00 M yaitu 96,52\%. Berdasarkan analisis XRD, PCC mempunyai bentuk kristal kalsit dan vaterit dengan ukuran kristal 13,95-14,02 nm, analisis dengan SEM menunjukkan partikel berbentuk kubus (kalsit) dengan ukuran $2 \mu \mathrm{m}$.
\end{abstract}

\section{PENDAHULUAN}

Penggunaan batu kapur pada saat ini hanya terbatas sebagai kapur tohor, kapur pasang dan bahan baku industri semen, sehingga masih bernilai ekonomis rendah. Oleh karena itu perlu adanya usaha untuk meningkatkan nilai mutu produk batu kapur dengan mengolahnya menjadi produk yang lebih berdaya guna dalam industri seperti Precipitated Calcium Carbonate (PCC), sehingga berdaya saing di pasar nasional maupun pasar internasional.

PCC adalah produk pengolahan batu kapur melalui serangkaian reaksi kimia. Secara teknis PCC memiliki keistimewaan seperti ukuran partikel yang kecil (skala mikro) dan homogen. Dengan keistimewaan karakteristik yang dimilikinya, pemakaian PCC dalam industri menjadi semakin luas. Saat ini PCC telah digunakan sebagai aditif pada obat-obatan, makanan, kertas, plastik dan tinta ${ }^{[1]}$. PCC dapat disintesis dari batu kapur dengan tiga metoda yaitu metoda karbonasi, metoda kaustik soda dan metoda solvay. Pada metoda kaustik soda, batu kapur dikalsinasi menjadi $\mathrm{CaO}$, lalu dihidrasi menjadi $\mathrm{Ca}(\mathrm{OH})_{2}$ dan kemudian direaksikan dengan larutan natrium karbonat
$\left(\mathrm{Na}_{2} \mathrm{CO}_{3}\right)$ sehingga terbentuk endapan $\mathrm{CaCO}_{3}$ (PCC). Akan tetapi pada metoda ini rendemen PCC yang dihasilkan relatif rendah, karena dibatasi oleh kelarutan $\mathrm{Ca}(\mathrm{OH})_{2}$ yang kecil $\left(\mathrm{Ksp} \mathrm{Ca}(\mathrm{OH})_{2} 7,9 \times 10^{-6}\right)^{[2,3]}$.

Modifikasi pembentukan PCC dilakukan dengan menambahkan larutan asam nitrat pada batu kapur yang sudah dikalsinasi sehingga terbentuk garam kalsium yang mudah larut. Hasil perlakuan disaring dan filtrat direaksikan dengan larutan natrium karbonat membentuk endapan kalsium karbonat (PCC).

Menurut Ahn et.al ${ }^{[4]}$ larutan asam nitrat dapat meningkatkan kelarutan ion kalsium dalam susu $\mathrm{Ca}(\mathrm{OH})_{2}$ dan asam nitrat merupakan asam kuat yang dapat bereaksi keras dengan oksida logam seperti kalsium oksida membentuk garam yang mudah larut ${ }^{[5]}$.

\section{METODOLOGI}

\section{Alat dan Bahan}

Alat-alat yang digunakan adalah peralatan gelas, termometer, hot plate stirrer, pengaduk 
magnetik, neraca analitis, kertas saring, pompa vakum, $\mathrm{pH}$ meter, XRF, XRD, foto optik, dan SEM. Adapun bahan yang digunakan adalah batu kapur yang diambil dari salah satu deposit di Sumatera barat, $\mathrm{Na}_{2} \mathrm{CO}_{3}, \mathrm{HNO}_{3}$ pekat, akuabides, dan etanol.

\section{Prosedur Kerja}

Sampel berupa batu kapur diambil dari Bukit Tui Padang Panjang, Halaban 50 Kota, Lintau Buo, Solok dan Indarung. Kemudian dihaluskan dan dianalisis dengan menggunakan XRF. Sampel yang telah digiling dan diayak dengan ukuran partikel 45 $\mu \mathrm{m}$, dibakar dalam furnace dengan suhu $1000^{\circ} \mathrm{C}$ selama \pm 20 menit, kemudian disimpan dalam desikator.

Sebanyak 5,6 g produk hasil kalsinasi ditambahkan larutan $\mathrm{HNO}_{3}$ (Variasi konsentrasi 1,$00 ; 1,25 ; 1,50 ; 1,75$ dan $2,00 \mathrm{M}$ ) sebanyak $9 \mathrm{~mL}$ dan akuabides $191 \mathrm{~mL}$ hingga volume campuran menjadi $200 \mathrm{~mL}$ lalu diaduk selama 15 menit pada suhu $65^{\circ} \mathrm{C}$ dengan kecepatan 700 rpm, kemudian disaring.

Filtrat ditambahkan larutan $\mathrm{Na}_{2} \mathrm{CO}_{3}$ sebanyak $150 \mathrm{~mL}$ dengan variasi konsentrasi 0,$25 ; 0,50$; 1,$00 ; 1,50$; dan 2,00 M dengan kecepatan alir $2,5 \mathrm{~mL} /$ menit. Reaksi dilakukan dengan variasi $30,45,60,90$, dan 120 menit dengan kecepatan pengadukan $400 \mathrm{rpm}$, setelah itu campuran didiamkan hingga endapan dan larutan tampak terpisah ( \pm 20 menit). Produk yang dihasilkan dianalisis dengan foto optik, XRD, XRF dan SEM.

\section{HASIL DAN PEMBAHASAN}

Komposisi batu kapur yang dianalisis diambil dari 5 daerah berbeda di Sumatera Barat yaitu, Solok (A),50 Kota (B) , Lintau Buo (C), Padang Panjang (D), dan Indarung Padang (E). Komposisi kimia masing-masing sampel ditunjukkan pada Tabel 1.

Hasil analisis XRF menunjukkan bahwa kandungan $\mathrm{CaO}$ dari setiap sampel tidak jauh berbeda yaitu sekitar 52 sampai $55 \%$. Kandungan $\mathrm{CaO}$ terbanyak terdapat pada batu kapur Lintau Buo dan Halaban, yaitu 54,93\% dan 54,85\%. Kedua jenis batu kapur termasuk batu kapur kualitas tinggi karena kandungan CaO-nya $>54 \%$, sehingga dapat digunakan sebagai bahan baku pembuatan $\mathrm{PCC}^{[6]}$.

Larutan $\mathrm{Na}_{2} \mathrm{CO}_{3}$ adalah sebagai sumber ion karbonat yang akan bereaksi dengan ion kalsium, membentuk endapan kalsium karbonat (PCC).

$$
\mathrm{Ca}^{2+}(\mathrm{aq})+\mathrm{CO}_{3}^{2-}(\mathrm{aq}) \longrightarrow \mathrm{CaCO}_{3}(\mathrm{~s})
$$

Hasil pengukuran rendemen PCC pada beberapa konsentrasi $\mathrm{Na}_{2} \mathrm{CO}_{3}$ dapat dilihat pada Gambar 1.

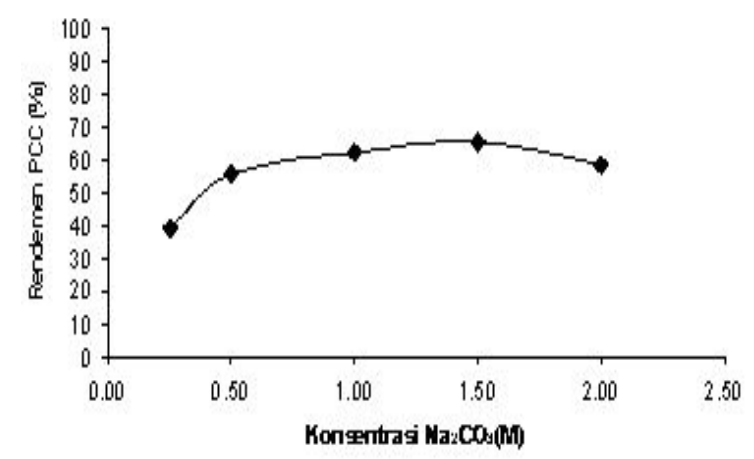

Gambar 1. Pengaruh konsentrasi $\mathrm{Na}_{2} \mathrm{CO}_{3}$ terhadap rendemen $\mathrm{PCC}$,waktu reaksi 60 menit, kecepatan alir $\mathrm{Na}_{2} \mathrm{CO}_{3} 2,5 \mathrm{~mL} / \mathrm{menit}$.

Gambar 1 memperlihatkan bahwa pada konsentrasi natrium karbonat rendah $(0,25 \mathrm{M}$ dan $1,50 \mathrm{M}$ ) didapatkan rendemen PCC rendah pula. Pada keadaan ini jumlah mol 0,25 M $\mathrm{Na}_{2} \mathrm{CO}_{3}$ setara dengan $0,0375 \mathrm{~mol}$ dan $0,50 \mathrm{M}$ $\mathrm{Na}_{2} \mathrm{CO}_{3}$ setara dengan $0,075 \mathrm{~mol}$ dan jumlah mol ion kalsium secara teoritis adalah $0,09 \mathrm{~mol}$ dengan anggapan semua $\mathrm{CaO}$ larut menghasilkan ion $\mathrm{Ca}^{2+}$.

Secara teoritis, untuk menghasilkan $\mathrm{CaCO}_{3}$ dibutuhkan ion $\mathrm{Ca}^{2+}$ dan ion $\mathrm{CO}_{3}{ }^{2-}$ dengan perbandingan mol $1: 1$. Sedangkan pada kedua konsentrasi di atas perbandingan ini belum tercapai, dimana jumlah mol ion $\mathrm{CO}_{3}{ }^{2-}$ masih rendah dibandingkan jumlah mol $\mathrm{Ca}^{2+}$ teoritis, dengan demikian dapat disarankan rendahnya rendemen PCC disebabkan kurangnya jumlah ion $\mathrm{CO}_{3}{ }^{2-}$ untuk mengubah semua ion kalsium menjadi endapan $\mathrm{CaCO}_{3}$ (PCC), sehingga rendemen yang dihasilkan pun semakin banyak. 
Tabel 1. Komposisi kimia batu kapur

\begin{tabular}{c|ccccc}
\hline \multirow{2}{*}{$\begin{array}{c}\text { Senyawa } \\
(\%)\end{array}$} & \multicolumn{5}{|c}{ Daerah Sampel } \\
\cline { 2 - 6 } & $\mathrm{A}$ & $\mathrm{B}$ & $\mathrm{C}$ & $\mathrm{D}$ & $\mathrm{E}$ \\
\hline $\mathrm{CaO}$ & 52.79 & 54.85 & 54.93 & 53.36 & 52.89 \\
$\mathrm{Fe}_{2} \mathrm{O}_{3}$ & 0.35 & 0.32 & 0.33 & 0.38 & 0.35 \\
$\mathrm{MgO}$ & 0.84 & 0.66 & 0.67 & 0.14 & 0.83 \\
$\mathrm{SiO}_{2}$ & 4.28 & 2.46 & 2.35 & 2.06 & 4.06 \\
$\mathrm{Al}_{2} \mathrm{O}_{3}$ & 0.43 & 0.31 & 0.31 & 0.68 & 0.41 \\
$\mathrm{LOI}^{*}$ & 42.41 & 42.46 & 43.91 & 42.09 & 42.46 \\
\hline
\end{tabular}

Hasil analisis foto optik PCC pada kondisi optimum dengan perbesaran $400 \mathrm{kali}$, dapat dilihat pada Gambar 2 yang menunjukkan bahwa partikel yang dihasilkan mempunyai bentuk yang sama dan membentuk aglomerasi. Menurut Jung et.al (2004) adanya garam monovalen dalam larutan $\left(\mathrm{NaNO}_{3}, \mathrm{KNO}_{3}\right.$, $\mathrm{NaCl}$ ) dapat menetralkan gaya tolak-menolak antar muatan listrik kristal yang berlawanan sehingga efisiensi tumbukan meningkat dan menyebabkan terjadinya aglomerasi.

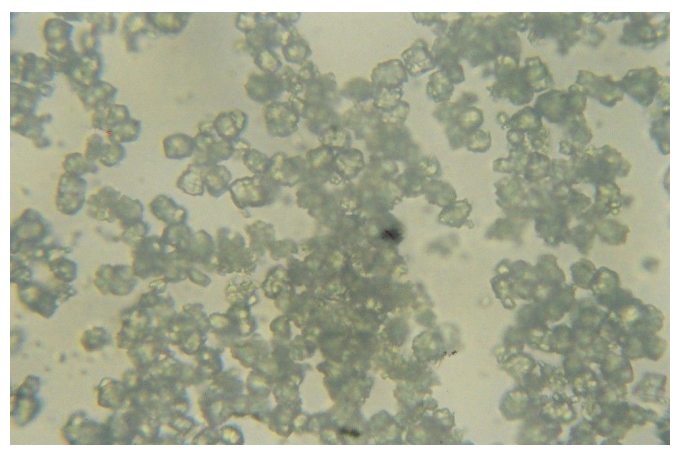

Gambar 2. Foto optik PCC dengan $\mathrm{Na}_{2} \mathrm{CO}_{3} 2,00$ M dengan perbesaran 400x .

Untuk mengetahui waktu optimum reaksi yang menghasilkan rendemen tertinggi dilakukan 5 variasi waktu reaksi berdasarkan lamanya pengadukan yaitu 30, 45, 60, 90 dan 120 menit. Reaksi dilakukan pada suhu kamar, konsentrasi $\mathrm{Na}_{2} \mathrm{CO}_{3} \quad 1,50 \mathrm{M}$ dan konsentrasi $\mathrm{HNO}_{3} 2 \mathrm{M}$ ditunjukkan pada Gambar 3.

Gambar 3 memperlihatkan bahwa waktu reaksi mempengaruhi rendemen PCC yang dihasilkan. Pada waktu reaksi 30 menit, rendemen yang dihasilkan memiliki nilai terendah. Sedangkan pada waktu 45, 60 dan 90 menit rendemen yang dihasilkan hampir sama, yakni berkisar antar 63 sampai $65 \%$ dengan nilai tertinggi didapatkan pada waktu 60 menit. Waktu yang reaksi terlalu cepat akan menyebabkan kesempurnaan reaksi belum tercapai sehingga produk yang dihasilkan pun akan lebih kecil dari yang seharusnya.

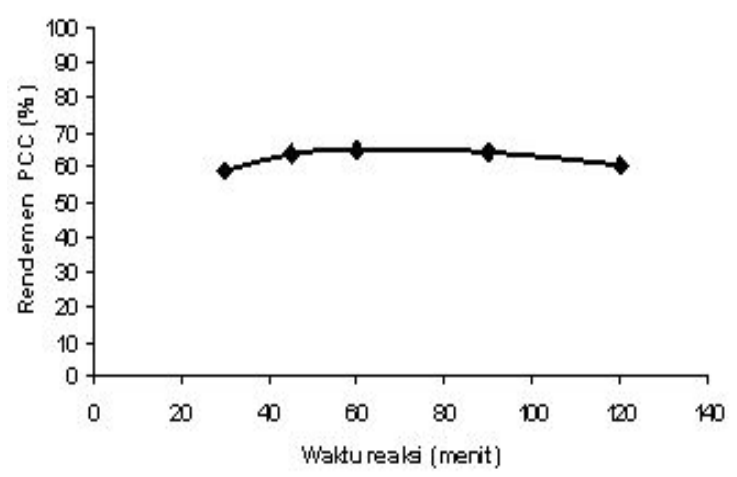

Gambar 3. Pengaruh waktu reaksi terhadap rendemen PCC pada konsentrasi $\mathrm{Na}_{2} \mathrm{CO}_{3} 1,50 \mathrm{M}$.

Variasi konsentrasi larutan asam nitrat pada saat pelarutan $\mathrm{CaO}$ dengan asam nitrat, dengan bobot $\mathrm{CaO}$ konstan yaitu 5,6 g. Pengaruh konsentrasi $\mathrm{HNO}_{3}$ pada rendemen PCC yang dihasilkan dapat dilihat pada Gambar 4.

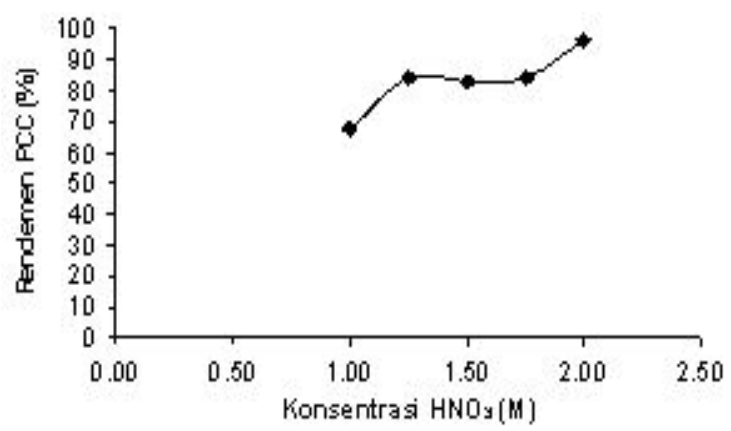

Gambar 4. Pengaruh konsentrasi $\mathrm{HNO}_{3}$ terhadap rendemen PCC, waktu reaksi PCC 60 menit, pada suhu kamar dan konsentrasi $\mathrm{Na}_{2} \mathrm{CO}_{3} 1,50 \mathrm{M}$.

Gambar 4 menunjukkan bahwa semakin besar konsentrasi $\mathrm{HNO}_{3}$ maka rendemen $\mathrm{PCC}$ yang dihasilkan semakin tinggi. Gejala ini mulai 
dapat diamati pada saat reaksi antara $\mathrm{HNO}_{3}$ dengan $\mathrm{CaO}$. Pada konsentrasi $\mathrm{HNO}_{3} 1,00 \mathrm{M}$, campuran berupa suspensi yang ketika disaring, menyisakan residu berupa serbuk yang bewarna lebih kuning dibandingkan dengan $\mathrm{CaO}$ awal. Sedangkan pada konsentrasi $\mathrm{HNO}_{3}$ mulai dari 1,$25 ; 1,50 ; 1,75$ dan $2,00 \mathrm{M}$, campuran tampak seperti larutan berwarna kuning kecoklatan, dan ketika disaring menyisakan sangat sedikit residu yang berwarna coklat pekat yang bobotnya sangat rendah dibandingkan dengan sampel yang menggunakan $\mathrm{HNO}_{3} 1,00 \mathrm{M}$.

Kemurnian PCC yang dihasilkan dianalisis dengan XRF. Hasil analisis ditunjukkan pada Tabel 2. Apabila kandungan senyawa kalsium dari PCC A dan B dibandingkan dengan bahan baku batu kapur maka didapatkan kandungan senyawa kalsium lebih tinggi pada PCC daripada bahan baku batu kapur. Jika dibandingkan dengan PCC standar, didapatkan jumlah pengotor PCC A lebih sedikit dibandingkan PCC standar, sedangkan pengotor pada PCC B lebih banyak dibandingkan PCC standar.

Menurut Thieman et.al ${ }^{[5]}$ asam nitrat merupakan senyawa yang mudah bereaksi dengan logam membentuk garam nitrat. Di samping itu menurut Brady dan Holum ${ }^{[2]}$, oksida logam mudah bereaksi dengan larutan asam.

Pola XRD PCC sampel Lintau Buo pada perlakuan asam nitrat 2,00 $\mathrm{M}$ dan $\mathrm{Na}_{2} \mathrm{CO}_{3} 1,50$ M dapat dilihat pada Gambar 5.

Tabel 2. Komposisi kimia PCC : Perlakuan $\mathrm{HNO}_{3} 1,00 \mathrm{M}(\mathrm{A})$, perlakuan $\mathrm{HNO}_{3} 2,00 \mathrm{M}$ (B).

\begin{tabular}{ccccc}
\hline \multirow{2}{*}{$\begin{array}{c}\text { Senyawa } \\
\text { Kimia }\end{array}$} & $\begin{array}{c}\text { BatuKapur } \\
(\%)\end{array}$ & $\mathrm{A}$ & $\mathrm{B}$ & Standar* \\
\cline { 3 - 5 } $\mathrm{CaO}$ & 54,93 & 55,36 & 55,39 & 55,59 \\
$\mathrm{Al}_{2} \mathrm{O}_{3}$ & 0,31 & 0,20 & 0,21 & 0.28 \\
$\mathrm{MgO}$ & 0,67 & 0 & 0,04 & 0.06 \\
$\mathrm{Fe}_{2} \mathrm{O}_{3}$ & 0,33 & 0 & 0,01 & 0 \\
$\mathrm{SiO}_{2}$ & 2,35 & 0 & 0 & 0 \\
\hline $\begin{array}{l}\mathrm{LOI} * \\
\text { O }\end{array}$ & 43,91 & 43,43 & 43,58 & 43.77 \\
\hline *CC sintesis yang diproduksi oleh WAKO Pure Chemical \\
Industries. Ltd \\
** LOI = Loss On Ignition
\end{tabular}

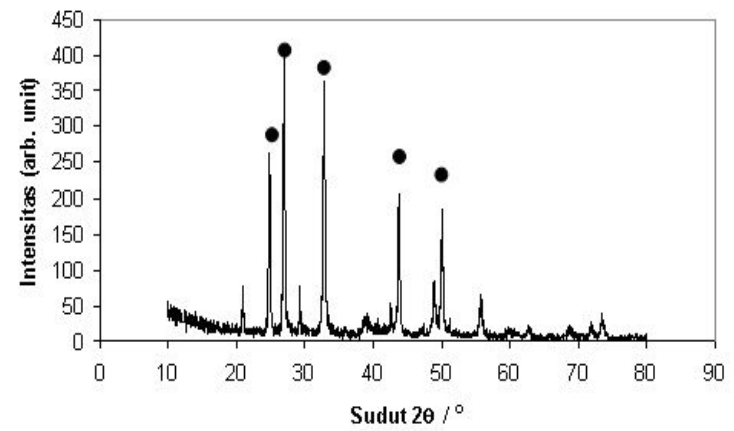

Gambar 5. Pola XRD PCC dengan perlakuan $\mathrm{HNO}_{3} \quad 2,0 \quad \mathrm{M}$, pereaksi $\mathrm{Na}_{2} \mathrm{CO}_{3} \quad 1,5 \mathrm{M}$ yang menghasilkan kalsit

Pada Gambar 5 dapat dilihat puncak difraksi maksimum terjadi pada $2 \theta$ sama dengan $29,51^{\circ}$. Hal ini menunjukkan bahwa kristal yang dihasilkan berupa kalsit dengan indeks miller 104. Selain itu terdapat pula puncakpuncak pendukung dengan sudut-sudut difraksi : $23,06^{\circ} ; 35,98^{\circ} ; 39,41^{\circ} ; 48,51^{\circ}$. Nilai ini sama dengan yang diperoleh Ahn et.al ${ }^{[4]}$ dan Rui-Juan ${ }^{[8]}$.

Kristal kalsium karbonat terdiri atas tiga polimorfik, yaitu kalsit, aragonit dan vaterit.

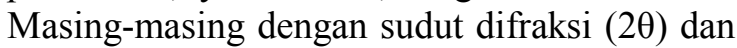
indeks miller yang berbeda. Kalsit mempunyai indeks miller 104 dan sudut difraksi $29,5^{\circ}$, aragonit 221 pada $2 \theta, 47^{\circ}$ dan vaterit 110 nilai $2 \theta, 25^{\circ}[7]$.

Hasil pengukuran SEM PCC dengan konsentrasi $\mathrm{HNO}_{3} 2,00 \mathrm{M}, \mathrm{Na}_{2} \mathrm{CO}_{3}$ 1,50 $\mathrm{M}$ dan waktu reaksi 60 menit ditunjukkan pada Gambar 6 yang menunjukkan bahwa bentuk kristal yang dihasilkan vaterit berbentuk bulat dengan ukuran $2 \mu \mathrm{m}$ dan campuran kalsit.

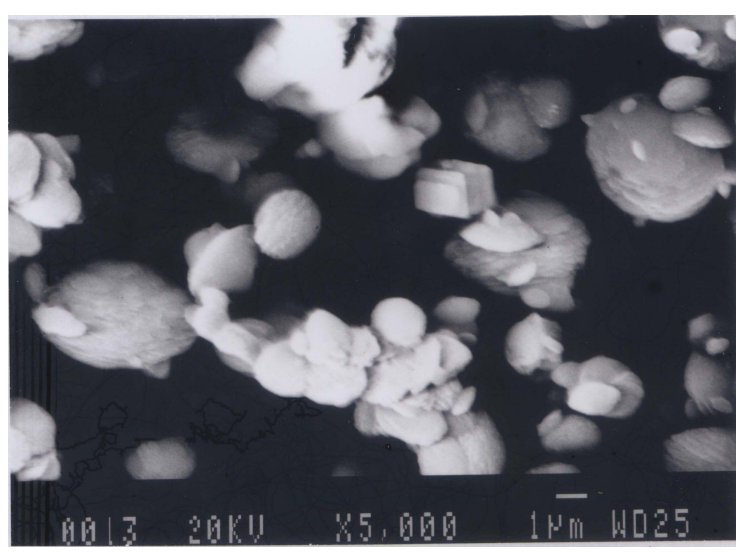

Gambar 6. Hasil SEM PCC pada perlakuan $\mathrm{HNO}_{3}$ $2,00 \mathrm{M}$ 
Menurut Lopez et.al ${ }^{[9]}$ vaterit dapat berubah menjadi kalsit dengan mediasi pelarut, dan Rui-Juan et.al ${ }^{[8]}$ melaporkan bahwa vaterit sensitif terhadap waktu reaksi dimana dengan lamanya waktu reaksi maka vaterit dapat berubah menjadi kalsit.

Kalsit mempunyai bentuk kristal rombohedral, kubus, scalenohedral, dan prismatik. Aragonit berbentuk cluster dan discrete needle-like, sedangkan vaterit dapat berbentuk bulat

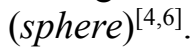

\section{KESIMPULAN}

Modifikasi metoda kaustik soda dapat meningkatkan rendemen PCC yang dihasilkan. Rendemen terbesar didapatkan pada konsentrasi natrium karbonat 1,50 $\mathrm{M}$ dengan waktu reaksi 60 menit dan perlakuan asam nitrat 2,00 M yaitu sebesar $96,52 \%$ dengan tingkat kemurnian 99,53\% dan bentuk kristal dominan vaterit, berbentuk bulat dengan ukuran 2,0 $\mu \mathrm{m}$.

\section{DAFTAR PUSTAKA}

1. Wang, L., Sondi, I., and Matijevic, E., 1999, Preparation of Uniform Needlike Aragonite Particles By Homogenous Precipation, Colloid and Interface Science., 218: 545.
2. Brady, J. E., and Holum, J.R., 1992, Chemistry The Study of Matter and its Changes. John Wiley \& Sons. New York.

3. Jamarun, N., Rahmadanis, Arif, S., 2005, Pengaruh Temperatur Karbonasi Pada Pembentukan PCC, J. Kimia Andalas., 11:(1).

4. Ahn, J.W., Kim, J.H., Park, H.S., Kim, J.A., Han, C., and Kim, H., 2005, Synthesis Single Phase Aragonite Precipitated Calcium Carbonate in $\mathrm{Ca}(\mathrm{OH})_{2}-\mathrm{Na}_{2} \mathrm{CO}_{3}$ $\mathrm{NaOH}$ Reaction system, J. Chem. Eng., 22(6): 852-856.

5. Thieman, M., 1991, Nitric Acid. Ullmans Encyclopedia of Industrial Chemistry (ed. Barbara Elvers, et. al) Vol. A. 17, Germany.

6. Azis, M., 1997, Kalsium Karbonat, Karakteristik serta Penggunanya dalam Industri, Makalah Teknik., Nomor 3 Tahun 6.

7. Christos, G. K., and Veganas, N.V., 2002, Calcium Carbonate Phase Analysis Using XRD and FT. Raman Spectrocopy, The Royal Society of Chemistry, 269-274.

8. Rui-Juan, Q., and Zhu, Y.Z., 2006, Microwave-Assisted Synthesis of Calcium (Vaterite) of Various Morphologies in Water-Ethylene Glycol Mixed Solvents, $J$. Phys. Chem B., 110: 8302-8306.

9. Lopez, M.A., Morales, G., and Clemente, R., 1996, J. Cryst Growth.,166: 1015. 